\title{
Gender, Sex and Traumatic Brain Injury: Transformative Science to Optimize Patient Outcomes
}

Tatyana Mollayeva and Angela Colantonio

\begin{abstract}
This paper presents highlights from a program of research addressing sex and gender among persons with traumatic brain injury (TBI) relevant to the Canadian context. Epidemiological trends based on health administrative data are examined, and their implications for policy and practice are considered. Further, the authors discuss the need to proactively address TBI in marginalized populations and in the workplace, two areas that have not received widespread attention.
\end{abstract}

\section{Introduction}

Emerging sex and gender trends have reshaped social institutions, and recent scientific breakthroughs affirm that sex- and gender-sensitive research is advancing the health sciences (ButlerJones 2012; Health Canada 2010; Tannenbaum et al. 2016). Explicit consideration of these interrelated concepts (described in Table 1) has also enhanced our understanding of the experience of traumatic brain injury (TBI) (Colantonio 2016). TBI is a historically neglected area of research, particularly among women. Given that TBI is a major cause of death and disability worldwide (World Health Organization 2006), further study is crucial. The economic impact is also significant (Chen et al. 2012). A recent report by the Public Health Agency of Canada (2014) forecasts that TBI is the costliest neurological condition, with costs of over $\$ 8$ billion by 2031 .

TABLE 1.

What is the difference between sex and gender?

\begin{tabular}{l|l}
\hline Sex & Gender \\
\hline $\begin{array}{l}\text { Typically refers to "... the biological } \\
\text { and physiological characteristics }\end{array}$ & $\begin{array}{l}\text { Typically refers to the "... socially } \\
\text { constructed roles, relationships, } \\
\text { that distinguish males from }\end{array}$ \\
$\begin{array}{l}\text { behaviours, relative power, and } \\
\text { females" }\end{array}$ & $\begin{array}{l}\text { other traits that societies ascribe to } \\
\text { women and men" }\end{array}$
\end{tabular}

- Although sex (male/female) and gender (men/women) are both commonly discussed as discrete and binary concepts, CIHR acknowledges that both are fluid and dynamic

- Sex and gender are interrelated; the relationships are complex

$\mathrm{CIHR}=$ Canadian Institutes of Health Research.

CIHR Institute of Gender and Health 2014; CIHR 2015

\section{Epidemiology Research Informing Prevention and Healthcare Policy}

Our research draws upon extensive population-based data available through our publicly funded healthcare system. Data on hospitalizations - an indicator of the incidence of more serious brain injury - show that males have a higher incidence of TBI than females, particularly during young adulthood (Colantonio et al. 2010b). This sex-specific distribution of hospitalization rates, however, converges in older adulthood, the fastest growing segment of the population. The high rate of hospitalization associated with TBI in older adults is largely attributable to falls (Saverino et al. 2016). Acute care providers should be aware that TBI may be misinterpreted as age-related cognitive decline or other conditions such as dementia. Older adults with TBI should not be ignored as candidates for rehabilitation, as our research indicates that they can make inpatient rehabilitation gains similar to those of younger adults (Chan et al. 2013a). Fall prevention should also address TBI risk (Chan et al. 2013b) in both primary and secondary prevention initiatives.

While sports-related concussions - a form of "mild" TBI - have garnered significant media attention, we have focused on work-related TBI (wrTBI) in non-elite occupations. Our population-based research in Canada and Australia illustrates that the male sex is associated with more severe and fatal wrTBIs (Chang et al. 2014, 2015; Colantonio et al. 2010a). However, when all levels of injury severity are considered, the data reveal that a greater proportion (42\%) of females are affected, with the highest incidence rates occurring among females working in the government sector (Colantonio 2010a).

Our research has also indicated potential gendered differences in the type of incident that contributes to injury (Amodio et al. 2017). Likewise, sex and gender appeared to affect victimization patterns in our epidemiological study of assault-precipitated wrTBI in Ontario (Mollayeva et al. 2016): female workers are at greater risk of sustaining wrTBI than male workers (59.1\% vs. $40.9 \%$ ), and they also sustain more injuries to body parts aside from the head and neck. Female victims of wrTBI caused by assault are disproportionally represented in the healthcare, social services and education sectors, 
whereas male victims show higher rates in law enforcement and public administration (Mollayeva et al. 2016).

An earlier qualitative study explored gender differences affecting return to work after TBI. Consistent with our hypothesis, we found through interviews with injured workers that gender has an impact on employability after injury. While professional and breadwinner roles were important to both men and women, women were more proactive in seeking medical and rehabilitation services. Individuals working in supportive and nurturing (i.e., feminine) occupations reported more positive return-to-work experiences after wrTBI than those in traditionally masculine professions (Stergiou-Kita et al. 2016).

Our laboratory also leads research in the understudied area of TBI resulting from intimate partner violence (IPV) (Snyder 2015, Statistics Canada 2015). Many injuries in this context are from battery to the face, head and neck, and/or strangulation, and elevated head injury rates of up to $92 \%$ among women survivors of IPV have been identified (Kwako et al. 2011; St. Ivany et al. 2016). TBI, because of violence, is also associated with poorer community integration after injury compared to nonviolent TBI (Kim et al. 2013). To identify the needs of women survivors of IPV and TBI, we conducted a workshop that included persons with lived experience and representatives from local and national agencies providing services to and advocacy on behalf of this population. We believe this workshop was the first of its kind in Canada (Brain Injury Canada 2016). While an extensive report is forthcoming, based on stakeholder input, we have concluded that major gaps in TBI IPV education exist and must be addressed.

Overall, our collaborative research on marginalized populations with TBI has shown that both men and women who are homeless have higher reported rates of TBI and associated comorbidities (Hwang et al. 2008). This trend is also evident among criminalized populations in Canada. We found that criminalized women reported the highest rates of adverse early life experiences, such as abuse (Colantonio et al. 2014), suggesting that a different approach to this marginalized population is required. Given that a significant percentage of TBIs occur before these negative events, proactive management may significantly reduce the cost of criminalization and homelessness.

When data were stratified and analyzed by sex, potential sex- and gender-sensitive predictors of rehabilitation outcomes became evident.

\section{Research on better understanding of risk factors and clinical/rehabilitation outcomes}

Multidisciplinary rehabilitation has been shown to effectively improve functional outcomes of persons with TBI. Our laboratory has been at the forefront of examining sex and gender in rehabilitation contexts so as to inform gaps in care. Our findings show that
$70.2 \%$ of TBI rehabilitation patients are male, with the greatest representation of female patients being in the older adult group (51\%) (Chan et al. 2016). Before stratification, sex as a covariate in the multivariable linear regression models was not a significant predictor of rehabilitation outcomes (Chan et al. 2016). When data were stratified and analyzed by sex, potential sex- and gendersensitive predictors of rehabilitation outcomes became evident. For example, injury due to motor vehicle collisions (MVCs), which is associated with supplemental health insurance, was independently associated with better outcomes for women (Chan et al. 2016). The presence of comorbidities was independently associated with poorer functional outcomes in men. Many predictors of functional outcome (such as age and markers of injury severity) were the same, and it is important to document these in future research.

\section{Clinical studies, person-centred research and personalized rehabilitation}

In 2016, Dr. Colantonio was guest editor of a special issue of the Archives of Physical Medicine and Rehabilitation entitled "Sex, Gender, and Traumatic Brain Injury." The articles in the special issue acknowledged the paucity of sex-stratified data and sex and gender analysis in TBI research, which may be hindering advancements in TBI prevention, management and treatment. The issue also featured analyses of perceived service provision inequities. For example, one study found that women perceived that they were referred less often to rehabilitation services if in parenting roles than if engaged in paid employment (Haag et al. 2016). The issue also highlighted the need for journals to require and enforce more sex- and gender-based reporting of findings in articles to better inform policy and practice. A systematic review of prognosis after mild TBI found that only $7 \%$ of the studies examined provided sex-stratified data (Cancelliere et al. 2016). Another population-based study of acquired brain injury found that females were twice as likely as males to not receive inpatient rehabilitation (Stock et al. 2016). These inequities need further exploration. It is important to note that there is no universal definition for gender; however, various constructs exist that provide ways to capture nonbinary experiences of gender. The Canadian Institutes of Health Research (CIHR) Institute of Gender and Health provides excellent resources for researchers and policy makers on this topic (CIHR 2015).

Isolating the influences of sex and gender in research results is not a simple task because the two are inextricably linked. For example, while sex hormones may affect behaviours associated with injury prevention and risk aversion, gender norms impose social roles and expectations that may expose individuals to either higher or lower risk. Because gender-informed social roles create epigenetic modifications that drive or modify differences between men and women, future research should consider that sex and gender are interconnected; however, accounting for both simultaneously in epidemiological methodology is complex. 


\section{Conclusion}

Our research provides compelling evidence that understanding sex and gender in the context of TBI is critical for prevention and management, both at the general population level and among vulnerable populations. Canadian-led research has been at the forefront of addressing TBI inequity and transforming research agendas globally. It is imperative that significant leadership opportunities and resources be dedicated to sex and gender champions in research to continue to advance this important work. $\mathrm{HQ}$

\section{Acknowledgements}

The authors thank Natalia Smith, Sandra Sokoloff and Lin Haag for their editorial support. Funding for this study was received from the Canadian Institutes of Health Research (CGW-126580), the National Institutes of Health (1R21HD089106-01), the Alzheimer's Association (AARF-16-442937) and the Ontario Neurotrauma Foundation.

\section{References}

Amodio, V., H. Bruch, T. Mollayeva and A. Colantonio. 2017. "Using the Narratives of Ontarians with a Work-related Traumatic Brain Injury to Inform Injury Prevention: A Mixed Methods Study.” Work 56(3): 345-55. doi:10.3233/WOR-172492.

Brain Injury Canada. 2016. "Women and Brain Injury: Inaugural Gender Symposium.” Retrieved January 25, 2017. <http:// braininjurycanada.ca/wp-content/uploads/GenderSymposium_ OBIlink_Sep29.pdf>

Butler-Jones, D. 2012. The Chief Public Health Officer's Report on the State of Public Health in Canada, 2012: Influencing Health - The Importance of Sex and Gender. Ottawa, ON: Public Health Agency of Canada. Retrieved January 31, 2017. <www.phac-aspc.gc.cal cphorsphc-respcacsp/2012/index-eng.php>

Canadian Institutes of Health Research (CIHR). 2015. Definitions of Sex and Gender. Retrieved January 30, 2017. <http://www.cihr-irsc. gc.ca/e/47830.html>.

Cancelliere, C., J. Donovan and J.D. Cassidy. 2016. "Is Sex an Indicator of Prognosis after Mild Traumatic Brain Injury: A Systematic Analysis of the Findings of the World Health Organization Collaborating Centre Task Force on Mild Traumatic Brain Injury and the International Collaboration on Mild Traumatic Brain Injury Prognosis." Archives of Physical Medicine and Rehabilitation 97(Suppl. 2): S5-S18.

Chan, V., T. Mollayeva, K.J. Ottenbacher and A. Colantonio. 2016. "Sex-Specific Predictors of Inpatient Rehabilitation Outcomes after Traumatic Brain Injury." Archives of Physical Medicine and Rehabilitation 97(5): 772-80.

Chan, V., B. Zagorski, D. Parsons and A. Colantonio. 2013a. "Older Adults with Acquired Brain Injury: Outcomes after Inpatient Rehabilitation.” Canadian Journal of Aging 32(3): 278-86.

Chan, V., B. Zagorski, D. Parsons and A. Colantonio. 2013b. "Older Adults with Acquired Brain Injury: A Population-based Study.” BMC Geriatrics 13: 97.

Chang, V.C., E.N. Guerriero and A. Colantonio. 2015. "Epidemiology of Work-related Traumatic Brain Injury: A Systematic Review." American Journal of Industrial Medicine 58(4): 353-77.
Chang V.C., R. Ruseckaite, A. Collie and A. Colantonio. 2014. "Examining the Epidemiology of Work-related Traumatic Brain Injury through a Sex/Gender Lens: Analysis of Workers' Compensation Claims in Victoria, Australia." Occupational and Environmental Medicine 71(10): 695-703.

Chen, A., K. Bushmeneva, B. Zagorski, A. Colantonio, D. Parsons and W.P. Wodchis. 2012. "Direct Cost Associated with Acquired Brain Injury in Ontario.” BMC Neurology 12: 76.

CIHR Institute of Gender and Health. 2014. What is Gender? What is Sex? Retrieved January 31 2017. <http://www.cihr-irsc. gc.ca/e/48642.html>.

Colantonio, A. 2016. "Sex, Gender, and Traumatic Brain Injury: A Commentary." Archives of Physical Medicine and Rehabilitation 97(Suppl. 2): S1-S4.

Colantonio, A., D. Mroczek, J. Patel, J. Lewko, J. Fergenbaum and R. Brison. 2010a. "Examining Occupational Traumatic Brain Injury in Ontario." Canadian Journal of Public Health 101(Suppl. 1): S58-S62.

Colantonio, A., H. Kim, S. Allen, M. Asbridge, J. Petgrave and S. Brochu. 2014. "Traumatic Brain Injury and Early Life Experiences Among Men and Women in a Prison Population." Journal of Correctional Health Care 20(4): 271-79.

Colantonio, A., C. Saverino, B. Zagorski, B. Swaine, J. Lewko, S. Jaglal et al. 2010b. "Hospitalizations and Emergency Department Visits for TBI in Ontario." Canadian Journal of Neurological Sciences 37(6): 783-90.

Haag, H.L., M. Caringal, S. Sokoloff, P. Kontos, K. Yoshida and A. Colantonio. 2016. "Being a Woman with Acquired Brain Injury: Challenges and Implications for Practice." Archives of Physical Medicine and Rehabilitation 97(Suppl. 2): S64-S70.

Health Canada. 2010. Sex and Gender-based Analysis (SGBA). Retrieved January 20, 2017. <www.hc-sc.gc.ca/hl-vs/gender-genre/ analys/gender-sexes-eng.php>.

Hwang, S.W., A. Colantonio, S. Chiu, G. Tolomiczenko, A. Kiss, L. Cowan et al. 2008. "The Effect of Traumatic Brain Injury on the Health of Homeless People.” CMAJ 179(8): 779-84.

Kim, H., M. Bayle, D. Dawson, T. Mollayeva and A. Colantonio. 2013. "Characteristics and Functional Outcomes of Brain Injury Caused by Physical Assault in Canada: A Population-based Study from an Inpatient Rehabilitation Setting." Disability and Rehabilitation 35(26): 2213-20.

Kwako, L.E., N. Glass, J. Campbell, K.C. Melvin, T. Barr and J.M. Gill. 2011. "Traumatic Brain Injury in Intimate Partner Violence: A Critical Review of Outcomes and Mechanisms." Trauma, Violence and Abuse 12(3): 115-26.

Mollayeva, T., S. Mollayeva, J. Lewko and A. Colantonio. 2016. "Sex Differences in Work-related Traumatic Brain Injury due to Assault." Work 54(2): 415-23.

Public Health Agency of Canada. 2014. Mapping Connections: An Understanding of Neurological Conditions in Canada. Ottawa, ON: Public Health Agency of Canada. Retrieved January 31, 2017. <www. phac-aspc.gc.ca/publicat/cd-mc/mc-ec/assets/pdf/mc-ec-eng.pdf>.

Saverino, C., B. Swaine, S. Jaglal, J. Lewko, L. Vernich, J. Voth et al. 2016. "Rehospitalization after Traumatic Brain Injury: A Populationbased Study." Archives of Physical Medicine and Rehabilitation 97(Suppl. 2): S19-S25. 
St. Ivany, A. and Shminkey, D. 2016. "Intimate Partner Violence and Traumatic Brain Injury. State of the Science and Next Steps.” Family and Community Health 39(2): 129-37.

Statistics Canada. 2015. Family Violence in Canada: A Statistical Profile, 2013. Retrieved January 25, 2017. <www.statcan.gc.ca/dailyquotidien/150115/dq150115a-eng.htm>.

Stergiou-Kita, M., E. Mansfield, S. Sokoloff and A. Colantonio. 2016. "Gender Influences on Return to Work after Mild Traumatic Brain Injury." Archives of Physical Medicine and Rehabilitation 97(Suppl. 2): S40-S45.

Stock, D., C. Cowie, V. Chan, N. Cullen and A. Colantonio. 2016. "Determinants of Admission to Inpatient Rehabilitation among Acute Care Survivors of Hypoxic-Ischemic Brain Injury: A Prospective Population-wide Cohort Study." Archives of Physical Medicine and Rehabilitation 97(6): 885-91.

Snyder, R.L. 2015. "No Visible Bruises: Domestic Violence and Traumatic Brain Injury." The New Yorker. Retrieved January 25, 2017. $<$ http://www.newyorker.com/news/news-desk/the-unseen-victims-oftraumatic-brain-injury-from-domestic-violence>.

Tannenbaum, C., L. Greaves and I.D. Graham. 2016. "Why Sex and Gender Matter in Implementation Research." BMC Medical Research Methodology 16(1): 145.
World Health Organization. 2006. Projections of Mortality and Burden of Disease, 2002-2030. Deaths by Income Group. [Computer file] Retrieved December 10, 2016. <www.who.int/healthinfo/global_ burden_disease/projections2002/en/>.

\section{About the Authors}

Tatyana Mollayeva, MD, PhD, is a postdoctoral research fellow in the Acquired Brain Injury and Society Laboratory at the Toronto Rehabilitation Institute, University Health Network.

Angela Colantonio, PhD, OT Reg (Ont), FCAHS, is a CIHR Research Chair in Gender Work and Health; a professor in the Department of Occupational Science and Occupational Therapy; director of the Rehabilitation Sciences Institute at the University of Toronto; a senior scientist at the Toronto Rehabilitation Institute, University Health Network; and an adjunct scientist at the Institute for Clinical Evaluative Sciences. She may be contacted at angela.colantonio@utoronto.ca.

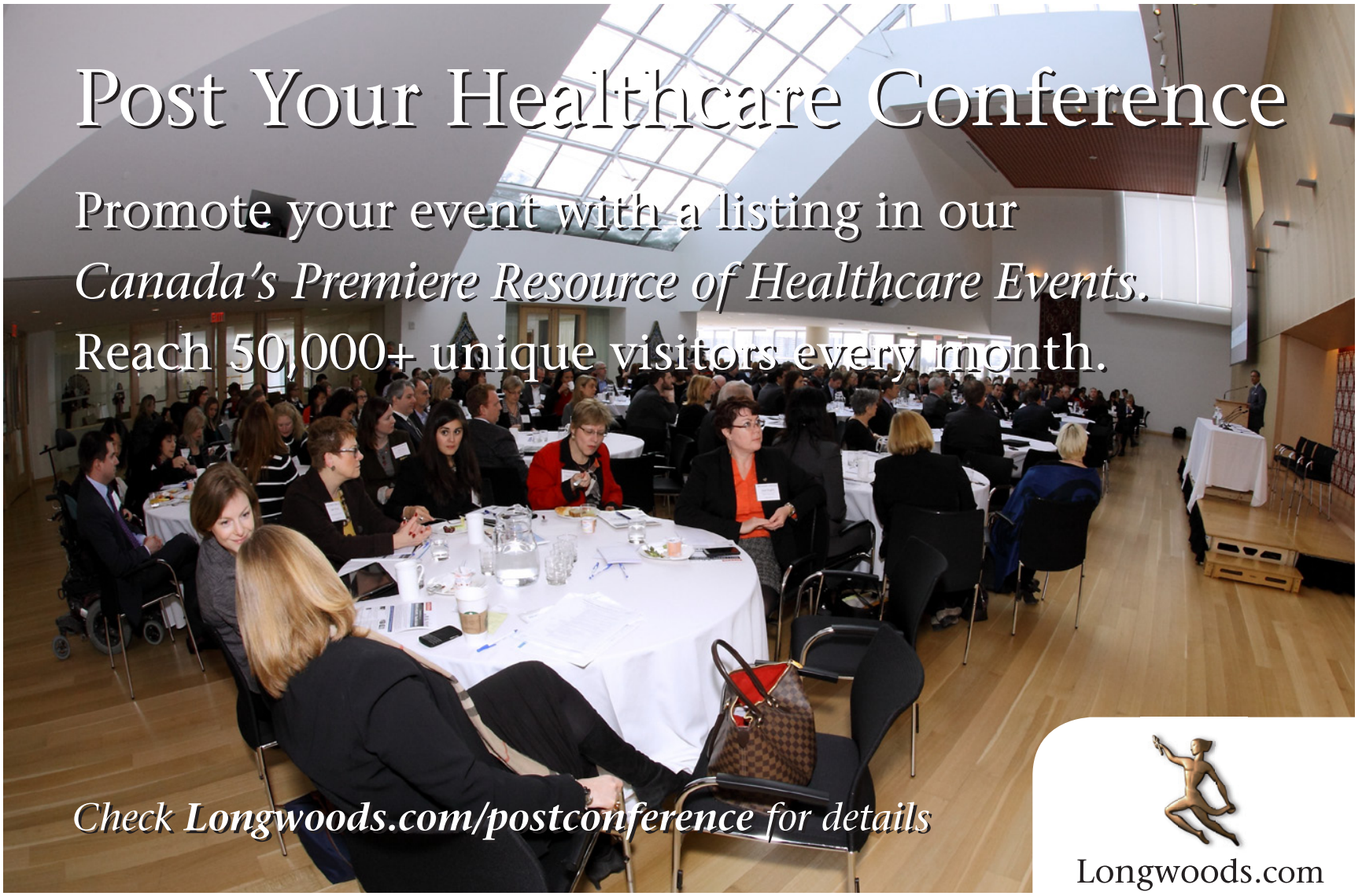

